\title{
Effect of Teacher Efficacy on Professional Development of Higher Secondary School Teachers of Kerala
}

\author{
Muhammed Amanulla. A.K ${ }^{(1)} \&$ Dr. P.K. Aruna ${ }^{(2)}$ \\ 1.Research Scholar,Department of Education, University of Calicut, Kerala, India. \\ 2.Associate Professor, Department of Education, University of Calicut, Kerala, India.
}

\begin{abstract}
This study was conducted to find out the effect of teacher efficacy on professional development of higher secondary school teachers of Kerala, India. For this 350 teachers were selected through stratified random sampling. Teacher efficacy scale and questionnaire of professional development of higher secondary school teachers were used for collecting the data. The t test has been applied to test the significance of difference between mean scores of teacher efficacy and professional development based on gender, type of school management and experience. The result revealed that there are significant differences between male and female teachers, government and private school teachers and more experienced and less experienced teachers in the mean scores of professional development. Similarly,teacher efficacy of government and private school teachers is significantly different. Teacher efficacy of male and female teachers and more experienced and less experienced are not significantly different. It was further revealed that there is no significant effect of teacher efficacy on professional development of teachers. It was concluded that no significant difference exists between the groups with regard to their professional development.
\end{abstract}

Keywords: Teacher efficacy, professional development, Higher secondary school

\section{Introduction}

"A light cannot light another one unless it keeps on burning". This oft-quoted proverb effectively explains the importance of professional development of teachers. Teacher is a lamp and his/her task is to light many other lamps. The lamp cannot light another lamps unless it keeps on burning. In order to keep a burning mind, the teacher should update his/her knowledge and competencies. Therefore, the professional development of a teacher is very essential. Teacher should refresh his/her knowledge, skill and other competencies according to the changing trends and new findings in the field of education. Knowledge explosion is the characteristic feature of modern world. Students in front of the teachers are getting abundance of knowledge from various sources. If the teacher is not aware of the new developments in the subject, he cannot influence in the all round development of the students.

Professional development is the provision of activities designed to advance the knowledge, skill and understanding of teachers in ways that lead to changes in their thinking and classroom behavior (Fenstermacher \& Berliner, 1983).(1). The activities include formal experiences like attending courses, workshops, seminars, mentoring, etc and informal experiences like reading professional publications and periodicals, watching television documentaries related to academic discipline, writing articles, books. Etc.

The National Curriculum Framework (NCF) $2005^{(2)}$ of India observes: Cultivation of professional competence, capacity to inspire and motivate students, devotion to duty, good scholarship and academic record, and quest for knowledge and excellence are all equally significant. Unless the level of professional competence does not rise along with betterment of material conditions, the status of teachers will not improve. Pursuit of excellence and establishment of reputation as a teacher go a long way in giving high status to teachers even if material benefits are not at par with other professions. (Acharya ramamurthy review commmittee) ${ }^{(3)}$. The professional preparation of teachers has been recognized to be crucial for the qualitative improvement of education since the 1960s (Kothari Commission, 1964-66) ${ }^{(4)}$

Teacher efficacy refers to a teacher's belief in his/her ability to make a difference in student learning (Ashton and Webb, 1986) ${ }^{(5)}$. Having a teacher with high efficacy beliefs can help students achieve more academically. Additionally, Guskey $(1987)^{(6)}$ found that teachers with high self-efficacy beliefs were more likely to report that they embraced innovative techniques in the classroom, especially those linked with mastery learning goals. High teacher efficacy also has been found to have a positive correlation with positive teacher practices and policies used in the classroom . Likewise, teachers with a high sense of personal and teacher efficacy had higher end-of-the-year goals for their students than those with low efficacy .

Higher secondary school students are in the adolescent period which is characterised as the period of stress and strife. They are studying different subjects in different combinations. So the higher secondary school teachers who are handling these students should have variety of competencies like behavioural management, 
guidance and counselling, class room management, awareness of new innovations in the subject, etc. So the teacher should achieve these qualities through a number of formal and informal learning activities along with the qualities attained from the pre service courses. Without which he/she cannot do the justice towards the profession.

Professional development in the case of teachers is just like academic achievement in the case of students. Although the student achievement is discussed in detail, the professional development is not much discussed. There are a lot of factors that influence in the professional development of teachers either directly or indirectly. The present study is an attempt to find out the effect of teacher efficacy on the professional development of a teachers.

\section{Objectives}

The objectives of the present study are the following:

* To find out whether there is any significant difference between the mean scores of

Professional development for the sample classified on the basis of gender, type of management of schools and Year of experience.

* To compare the mean scores of professional development of high teacher efficacy group, medium teacher efficacy group and low teacher efficacy group.

* To find out the correlation between Professional development and Teacher Efficacy of Higher secondary school teachers for the total sample and sub-samples.

\section{Hypotheses}

*There will be no significant difference in the mean scores of professional development for to sample classified on the basis of gender, type of management of schools and year of experience.

*Teacher Efficacy based groups differ significantly in their professional development.

*There will be significant relationship between the professional development and teacher efficacy for total and relevant sub samples.

\subsection{Sample}

\section{Methodology}

The study employed survey method. It was conducted on a sample of 350 higher secondary school teachers drawn from Malappuram and Palakkad districts of Kerala. The sample was selected by proportionate stratified sampling technique giving representation to factors like gender, type of management of schools and experience of teachers. The sample for semi-structured interview was 10 male and 10 female higher secondary school teachers.

\subsection{Tools}

The tools used for the study were questionnaire of Professional development of higher secondary school teachers, Teacher Efficacy scale and a semi structured interview schedule. Tools are developed and validated by the researcher.

\subsection{Statistical Technique Used}

The major statistical calculations employed are Pearson's Product moment correlation, Independent sample t-test, One way analysis of variance(ANOVA) and Scheffe's test of multiple comparison. Percentage scores were calculated for interview analysis.

\section{Results}

As a preliminary analysis the distribution of scores of both dependent and independent variables were examined. The important statistical constants like Mean, Median, Standard deviation, skewness and Kurtosis were computed for the total sample and are given in table 1.

Table-1.Statistical constants of the variables Professional development and Teacher efficacy.

\begin{tabular}{|l|l|l|l|}
\hline Sl,No & Statistical Constant & Professional development & Teacher efficacy \\
\hline 1 & Mean & 45.52 & 147.86 \\
\hline 2 & Median & 50 & 148 \\
\hline 3 & Mode & 45 & 120 \\
\hline 4 & Standard deviation & 19.11 & 14.80 \\
\hline 5 & Skewness & -0.49 & -0.11 \\
\hline
\end{tabular}




\begin{tabular}{|l|l|l|} 
Kurtosis & -0.25 & -0.65 \\
\hline
\end{tabular}

It is evident from the table that the mean scores of professional development and teacher efficacy are 45.52 and 147.86 respectively. Median values 50 and 148 denote that half of the participants scored above that scores respectively. The most frequent scores in the distribution are 45 and 120 respectively. The standard deviations are 19.11 and 14.80 respectively. The distribution is negatively skewed for both variables( -0.49 and 0.11 ) that informs that most of the participants scored on the higher end of the distribution. The indices of kurtosis $(-0.25$ and -0.65$)$ show that the distribution is platikurtic for both the variables.

\subsection{Professional development and teacher efficacy in sub-samples of higher secondary school teachers.}

Mean difference analysis was done to examine the difference between sub-samples in professional development and teacher efficacy. The sub-samples are based on gender, type of management of school and year of experience.(table-2)

Table-2. Mean difference analysis of professional development and teacher efficacy for sub-samples

\begin{tabular}{|c|c|c|c|c|c|}
\hline Variable & Sub-samples & $\mathbf{N}$ & Mean & SD & $\mathbf{t}$ \\
\hline $\begin{array}{l}\text { Professional } \\
\text { development }\end{array}$ & $\begin{array}{l}\text { Male } \\
\text { Female }\end{array}$ & $\begin{array}{l}224 \\
126\end{array}$ & $\begin{array}{l}47.70 \\
41.67\end{array}$ & $\begin{array}{l}20.97 \\
14.53\end{array}$ & $2.86^{*}$ \\
\hline Teacher efficacy & $\begin{array}{l}\text { Male } \\
\text { Female }\end{array}$ & $\begin{array}{l}224 \\
126\end{array}$ & $\begin{array}{l}147.14 \\
149.14\end{array}$ & $\begin{array}{l}16.35 \\
11.48\end{array}$ & 1.22 \\
\hline $\begin{array}{l}\text { Professional } \\
\text { development }\end{array}$ & $\begin{array}{l}\text { Government } \\
\text { Private }\end{array}$ & $\begin{array}{l}241 \\
109\end{array}$ & $\begin{array}{l}43.44 \\
50.14\end{array}$ & $\begin{array}{l}20.37 \\
15.02\end{array}$ & $3.07 *$ \\
\hline Teacher efficacy & $\begin{array}{l}\text { Government } \\
\text { Private }\end{array}$ & $\begin{array}{l}241 \\
109\end{array}$ & $\begin{array}{l}149.59 \\
144.06\end{array}$ & $\begin{array}{l}14.28 \\
15.25\end{array}$ & $3.28 *$ \\
\hline $\begin{array}{l}\text { Professional } \\
\text { development }\end{array}$ & $\begin{array}{l}\text { More experienced } \\
\text { Less experienced }\end{array}$ & $\begin{array}{l}162 \\
188\end{array}$ & $\begin{array}{l}53.53 \\
38.62\end{array}$ & $\begin{array}{l}17.06 \\
18.09\end{array}$ & $7.88^{*}$ \\
\hline Teacher efficacy & $\begin{array}{l}\text { More experienced } \\
\text { Less experienced }\end{array}$ & $\begin{array}{l}162 \\
188\end{array}$ & $\begin{array}{l}148.72 \\
147.12\end{array}$ & $\begin{array}{l}14.896 \\
14.70\end{array}$ & 1.01 \\
\hline
\end{tabular}

*significant at 0.01 level

There are significant differences between male and female teachers, government and private school teachers and more experienced and less experienced teachers in the mean scores of professional development. Similarly,teacher efficacy of government and private school teachers is significantly different. Teacher efficacy of male and female teachers and more experienced and less experienced are not significantly different.

\subsection{Summary of One-way ANOVA of Professional development by teacher efficacy}

Table-3. One-way ANOVA of Professional development by teacher efficacy

\begin{tabular}{|l|l|l|l|l|l|}
\hline Source of variation & Sum of squares & df & Mean square & F & Sig. \\
\hline Between Groups & 1924.24 & 2 & 962.12 & 2.66 & 0.07 \\
\hline Within Groups & 125493.03 & 347 & 361.65 & & \\
\hline Total & 127417.27 & 349 & & & \\
\hline
\end{tabular}

It is clear from the inspection of the table 3 that the main effect of teacher efficacy on professional development in the total sample found to be not significant. The obtained $\mathrm{F}$ value for between group and within group of the two variables is 2.66 which is lower than the table value for the corresponding degrees of freedom at 0.01 level. This implies that teacher efficacy has not significant effect on professional development of teachers.

\subsection{Post-hoc Analysis- Multiple comparisons}

This part of analysis was done as a post hoc comparison of mean scores of relevant groups of the independent variable showing significant main effect on the dependent variable.

Table 4- Scheffe's Test of Multiple Comparison of Teacher Efficacy on Professional Development based on three groups of Teacher Efficacy 


\begin{tabular}{|l|l|l|l|}
\hline Group Compared & Mean difference & Standard Error & Significance \\
\hline High and Medium group & 4.30 & 2.64 & Not significant \\
\hline High and Low group & 1.34 & 3.51 & Not significant \\
\hline Medium and Low group & 5.63 & 2.92 & Not significant \\
\hline
\end{tabular}

From the table 4 it is clear that high and medium teacher efficacy based group, high and low teacher efficacy based group and medium and low teacher efficacy based group do not differ in their professional development.

\subsection{Correlational Analysis}

Table-5. Relationship between Professional Development and Teacher Efficacy for total sample and sub

\begin{tabular}{|l|l|l|l|l|}
\hline Nature of Sample & Sample size & 'r' & 't' & Whether significant or not \\
\hline Total & 350 & 0.12 & 0.03 & Significant at 0.05 level \\
\hline Male & 224 & 0.17 & 0.01 & Significant at 0.05 level \\
\hline Female & 126 & -0.02 & 0.82 & Not significant \\
\hline Government & 241 & 0.13 & 0.04 & Significant at 0.05 level \\
\hline Private & 109 & 0.16 & 0.1 & Not significant \\
\hline More experienced & 162 & -0.01 & 0.95 & Not significant \\
\hline Less experienced & 188 & 0.20 & 0.01 & Significant at 0.01 level \\
\hline
\end{tabular}

The coefficient of correlation obtained for the total and six sub samples (male, government and less experienced teachers) is positive and significant at 0.05 level. This indicates that there is some sort of positive relationship between professional development and teacher accountability. The coefficient of correlation obtained for two sub samples (female and more experienced school teachers) is negative and negligible. The coefficient of correlation obtained for the sub sample (Private school) is positive and negligible.

\subsection{Percentage Analysis}

In order to know the perceived hindrances to the professional development activities by the teachers, an interview was conducted and analyzed as follows.

Table-6. Factors hindering professional development of teachers as opined by Male and female higher secondary school teachers

\begin{tabular}{|l|l|l|}
\hline \multirow{2}{*}{$\begin{array}{l}\text { Hindrances to professional } \\
\text { Development }\end{array}$} & Percentage of Responses & Percentage of Responses \\
\cline { 2 - 3 } & $\begin{array}{l}\text { Male } \\
\text { Teachers (10) }\end{array}$ & Female Teachers(10) \\
\hline Individual related & 60 & 70 \\
\hline Family related & 60 & 80 \\
\hline Administration related & 80 & 70 \\
\hline Students related & 60 & 30 \\
\hline School related & 30 & 20 \\
\hline Co workers related & 40 & 30 \\
\hline
\end{tabular}

Teachers opined that Administration related factors such as lack of incentives like promotion to higher post, FIP opportunity and increment in salary for $\mathrm{PhD}$, complexities of taking leave for higher studies, etc are significant in hindering professional development.(Male $80 \%$, female $70 \%$ ).Similarly, teachers especially females opined that family related factors like caring and rearing children, difficulty in leaving family for long time for higher study,etc are significant in hindering professional development.(female $80 \%$ male $60 \%$ ). Individual related factors such as lack of interest, laziness, absence of ambition, etc are important hindrance (female $70 \%$ male 60\%). Students related factors such as indiscipline, huge syllabus, heavy strength of class, etc (male60\% female 30\%) are also significant. On the basis of the scores of the interview of teachers it can be concluded that the higher scores of Male teachers could be attributed to almost all factors that seem to be hindering them as compared to female teachers.

\section{Conclusion}

1) There are significant differences between male and female teachers, government and private school teachers and more experienced and less experienced teachers in the mean scores of professional development. This indicates that factors like gender, management of schools and year of experience are the factors influencing the professional development of teachers. 
2) Teacher efficacy of government and private school teachers is significantly different. Teacher efficacy of male and female teachers and more experienced and less experienced are not significantly different. This indicates that management of school factor has influence in the teacher efficacy of teachers and the factors like gender and year of experience have no influence in the teacher efficacy of teachers.

3) The main effect of teacher efficacy on professional development in the total sample found to be not significant. This indicates that teacher efficacy has not significant effect on professional development of teachers.

4) A positive relationship was observed between professional development and teacher efficacy for total sample and sub samples like male, government, and less experienced teachers. This relationship indicates that increase in teacher efficacy will cause the increase in the professional development of teachers.

5) Administration related factors are more significant in the hindrances of professional development than other factors when both male and female teachers considered. As far as female teachers are concerned, family related factors and individual related factors are significant in the hindrances. Male teachers are scoring more in hindrances suggest that they are ready to take professional development activities but they cannot do it due to the hindrances.

The study has multi folded connotations. Since the study deals with the important issue of education, the results would be a great support to teachers and administrators. The following Suggestions can be summarized based on the study.

$>\quad$ Professional development of higher secondary school teachers is very important as they are handling the adolescent group. So they should be given more opportunities to professional development activities.

There are factors which influence in the professional development of teachers other than teacher efficacy. Secondary school teachers have many promotion opportunities in Kerala to the Post of Head master,(HM) Assistant Educational Officer(AEO), District educational Officer(DEO),Deputy director (DDE), Joint Director of public Instruction (JDPI) Additional Director of Public Instruction(ADPI),etc. But, the only promotion opportunity of Higher secondary school teachers is principal of higher secondary schools. This discrepancy should be solved to promote professional development behaviour of higher secondary school teachers.

$>\quad$ Lack of incentives is a major block in front of the teachers to go through various professional development activities. It should be solved by implementing some measures like promoting highly qualified higher secondary school teachers to colleges and universities, giving Faculty Improvement Programme (FIP) facility to higher secondary school teachers to do $\mathrm{PhD}$, giving increment to teachers having PhDs, etc

$>\quad$ Male teachers are scoring more in professional development and they are facing many blocks in the professional development than female teachers. So more opportunities must be given to female teachers to enhance their professional development behaviours.

\section{References}

[1]. Fenstermacher, G. D., \& Berliner, D. C. (1983). A conceptual frame work for the analysis of staff development. Unpublished manuscript, Santa Monica,California: Rand Corporation.

[2]. National Curriculum Frame Work (2005) .National Council of Educational Research and Training, New Delhi.

[3]. Report of the committee for review of national policy on education 1986, 26th December, 1990, New Delhi.

[4]. Report of Indian Education Commission,1964-66, National Council of Educational Research and Training, NIE Campus, Sri Aurobindo Marg, New Delhi.

[5]. Ashton, P.T. \& Webb, R.B. (1986). Teacher efficacy and student achievement. New York, N.Y.: Longman.

[6]. Guskey, T. R. (1988). Context variables that affect measures of teacher efficacy. Journal of Educational Research,81(1), 41-47. 